\title{
Verbenaceae no Parque Nacional do Caparaó, Serra da Mantiqueira, Brasil
}

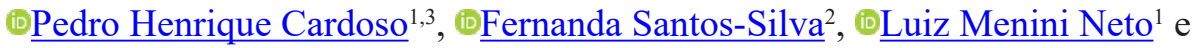 \\ [Dátima Regina Gonçalves Salimena ${ }^{1}$
}

Recebido: 7 junho 2019; aceito: 14 agosto 2019

Como citar: Cardoso, P.H., Santos-Silva, F., Menini Neto, L. \& Salimena, F.R.G. 2019. Verbenaceae no Parque Nacional do Caparaó, Serra da Mantiqueira, Brasil. Hoehnea 46: e652019. http://dx.doi.org/10.1590/2236-8906-65/2019.

ABSTRACT - (Verbenaceae in the Parque Nacional do Caparaó, Serra da Mantiqueira, Brazil). Verbenaceae currently comprises 35 genera and around 800 species distributed in the Americas, Africa, Asia, Europe and Oceania. In Brazil, there are 16 genera and approximately 280 species, with higher richness in the Cerrado and the Atlantic Forest, mainly in campos rupestres and campos de altitude. The Parque Nacional do Caparaó is located in the Serra da Mantiqueira, the border of Minas Gerais and Espírito Santo States. This park stands out due to the presence of the highest point in the Southeast of Brazil, the Pico da Bandeira, with 2,890 $\mathrm{m}$ of elevation. The vegetation comprises different phytophysiognomies including dense ombrophilous forest (montane and high montane), montane semideciduous seasonal forest and campos de altitude. Verbenaceae in this conservation unit is represented by five genera and nine infrageneric taxa including two possible new species belonging to the genera Lantana and Lippia, in addition to Citharexylum solanaceum, Glandularia lobata, Lantana fucata, L. nivea, L. robusta, Stachytarpheta cayennensis, and Verbena rigida. The occurrence of L. nivea is confirmed for Brazil, with the first record for Espírito Santo State. We present an identification key, descriptions, photograph plates and comments on the ecology, taxonomy and geographic distribution of the taxa.

Keywords: Atlantic Forest, Espírito Santo, Lamiales, Minas Gerais, taxonomy

RESUMO - (Verbenaceae no Parque Nacional do Caparaó, Serra da Mantiqueira, Brasil). Verbenaceae atualmente compreende 35 gêneros e cerca de 800 espécies distribuídas nas Américas, África, Ásia, Europa e Oceania. No Brasil são encontrados 16 gêneros e aproximadamente 280 espécies, com maior riqueza no Cerrado e Floresta Atlântica, principalmente nos campos rupestres e campos de altitude. O Parque Nacional do Caparaó está localizado na Serra da Mantiqueira, na divisa dos Estados de Minas Gerais e Espírito Santo. Esse parque destaca-se por apresentar o ponto de maior altitude da Região Sudeste do Brasil, o Pico da Bandeira, com 2.890 m. Possui vegetação representada por diferentes fitofisionomias, as quais incluem formações de floresta ombrófila densa (montana e alto montana), floresta estacional semidecidual montana e campos de altitude. Verbenaceae está representada nesta Unidade de Conservação por cinco gêneros e nove táxons, incluindo duas possíveis espécies novas de Lantana e Lippia, além de Citharexylum solanaceum, Glandularia lobata, Lantana fucata, L. nivea, L. robusta, Stachytarpheta cayennensis e Verbena rigida. A ocorrência de L. nivea é confirmada para o Brasil, sendo registrada pela primeira vez para o Estado do Espírito Santo. Nós apresentamos uma chave de identificação, descrições, pranchas de fotografias e comentários sobre a ecologia, taxonomia e distribuição geográfica dos táxons.

Palavras-chave: Espírito Santo, Floresta Atlântica, Lamiales, Minas Gerais, taxonomia

\section{Introdução}

Verbenaceae J.St.-Hil. compreende atualmente 35 gêneros e cerca de 800 espécies distribuídas principalmente na Região Neotropical, com poucos táxons na África, Ásia, Europa e Oceania (Atkins
2004, Marx et al. 2010). Os principais centros de diversidade da família são as regiões subtropicais e subáridas da América do Sul e as cordilheiras do México central e dos Andes (Sanders 2001). O Brasil está representado por 16 gêneros e aproximadamente 280 espécies, com maior riqueza no Cerrado e Floresta

1. Universidade Federal de Juiz de Fora, Instituto de Ciências Biológicas, Campus Universitário, Rua José Lourenço Kelmer, s/n - São Pedro, 36036-900 Juiz de Fora, MG, Brasil

2 Universidade Estadual do Sudoeste da Bahia, Departamento de Ciências Exatas e Naturais, Campus Itapetinga, 45700-000 Itapetinga, BA, Brasil

3. Autor para correspondência: pedro.cardoso@ecologia.ufjf.br 
Atlântica, principalmente nos campos rupestres e campos de altitude (BFG 2018).

A partir de estudos filogenéticos uma nova circunscrição foi proposta para Verbenaceae (Cantino 1992a, 1992b, Cantino et al. 1992), resultando na transferência de cerca de 50 gêneros incluídos na subfamília Viticoideae Briq. para Lamiaceae (Olmstead 2000, Wagstaff \& Olmstead 1997). Com esta delimitação Verbenaceae é considerada atualmente monofilética, representada pelos padrões morfológicos da subfamília Verbenoideae Briq., distinguindo-se de Lamiaceae pelas inflorescências racemosas e pólen com exina espessada próximo às aberturas (Judd et al. 2009). A família engloba espécies herbáceas, subarbustivas, arbustivas, arbóreas ou lianescentes, com tricomas tectores e glandulares; ramos inermes ou aculeados; folhas simples, sésseis ou pecioladas, opostas ou verticiladas, raro alternas; com inflorescências racemosas; brácteas verdes ou coloridas; flores sésseis ou pediceladas; cálice gamossépalo, persistente no fruto; corola gamopétala, estames 4-5, geralmente didínamos, ou 2 férteis e 2 estaminódios; ovário súpero, óvulos 1 por lóculo, estilete terminal. Fruto do tipo drupa ou esquizocarpo (Atkins 2004).

O primeiro tratamento de Verbenaceae para o Brasil foi apresentado por Schauer (1847). Desde então, revisões taxonômicas especificamente sobre os táxons brasileiros foram realizadas para os gêneros Lantana (Silva 1999), Stachytarpheta (Atkins 2005) e Glandularia (O’Leary \& Thode 2016), além das contribuições de floras estaduais [para o Distrito Federal (Salimena et al. 2015), Goiás e Tocantins (Salimena et al. 2016)] e locais [para Mucugê (Harley \& Simmons 1986), Pico das Almas (Atkins 1995), APA Cairuçu (Luizi-Ponzo 1997), Serra do Cipó (Salimena-Pires \& Giulietti 1998), Ilha do Cardoso (Salimena 2000); Grão Mogol (Salimena \& Silva 2009), região do Xingó entre Alagoas e Sergipe (Santos et al. 2009), em um trecho da ESEC Raso da Catarina na Bahia (Melo et al. 2010), Parque Estadual do Ibitipoca (Cruz \& Salimena 2017), Reserva Biológica da Represa do Grama (Cardoso et al. 2017), Serra Negra (Cardoso et al. 2018a), Serra dos Carajás (Cardoso et al. 2018b), Parque Estadual da Serra do Papagaio (Cardoso et al. dados não publicados), Parque Nacional do Itatiaia (Santiago et al. dados não publicados) e Parque Nacional da Serra da Canastra (Cardoso et al. dados não publicados)].

A Serra da Mantiqueira é uma cadeia montanhosa situada na Floresta Atlântica, ao longo da Região Sudeste do Brasil, sendo considerada uma área prioritária para a conservação de nascentes e espécies endêmicas (Saout et al. 2013, Gonzaga \& Menini Neto 2017). Com o intuito de assegurar a proteção da biodiversidade da Serra da Mantiqueira, existem algumas Unidades de Conservação na região, sendo as principais os parques nacionais do Itatiaia e Caparaó e os parques estaduais do Ibitipoca, Serra do Brigadeiro, Serra do Papagaio, Pedra Selada e Campos do Jordão (Gonzaga \& Menini Neto 2017).

A região do Parque Nacional do Caparaó teve sua primeira expedição científica comprovada em 1880, quando C.A.W. Schwacke realizou uma excursão ao maciço do Caparaó, para o estudo da flora e fauna do local (Santos 2004). O Parque Nacional do Caparaó (PNC) foi oficialmente instituído em 1961, sendo somente implementado em 1979 (Santos 2004, ICMBio 2015). Vários botânicos coletaram na região contribuindo para o registro da flora, com destaque para A. C. Brade, A. Glaziou, M. B. Foster, G. Hatschbach, M. Brugger, L. Krieger, V. C. Souza e L. Leoni (Mota 2012). Em relação aos trabalhos taxonômicos sobre a flora do Caparaó, foram publicados tratamentos para vários grupos como: Violaceae (Souza \& Souza 200), Plantaginaceae (Souza \& Souza 2002), Ericaceae (Romão \& Souza, 2003), Gesneriaceae (Leoni \& Chautems 2004), Eriocaulaceae (Trovó et al. 2006), Melastomataceae (Faria et al. 2006), Myrtaceae (Mazine \& Souza 2008), Begoniaceae (Feliciano et al. 2010), Laeliinae-Orchidaceae (Forster \& Souza 2013) e Bromeliaceae (Mota et al. 2016).

O presente estudo compreende a flora de Verbenaceae no PNC, contribuindo com o conhecimento taxonômico e biogeográfico da família na região da Serra da Mantiqueira, e com manejo e conservação da área. São apresentadas descrições, chave de identificação, fotografias, e comentários taxonômicos, ecológicos e de distribuição geográfica para os táxons.

\section{Material e métodos}

O Parque Nacional do Caparaó (PNC) está situado na Serra do Caparaó (20 ${ }^{\circ} 1^{\prime}-20^{\circ} 37^{\prime} \mathrm{S}$ e $41^{\circ} 43^{\prime}$ $\left.41^{\circ} 53^{\prime} \mathrm{W}\right)$, sendo parte da Serra da Mantiqueira, a leste do Estado de Minas Gerais e sudeste do Espírito Santo (figura 1), abrangendo parte dos municípios de Alto Caparaó, Alto Jequitibá, Caparaó, Divino, Espera Feliz, Manhuaçu, Presidente Soares, Lajinha em Minas Gerais e Alegre, Divino de São Lourenço, Dores do Rio Preto, Iúna, Irupi e Ibitirama no Estado do Espírito Santo (compreendendo 79,4\% da área total 


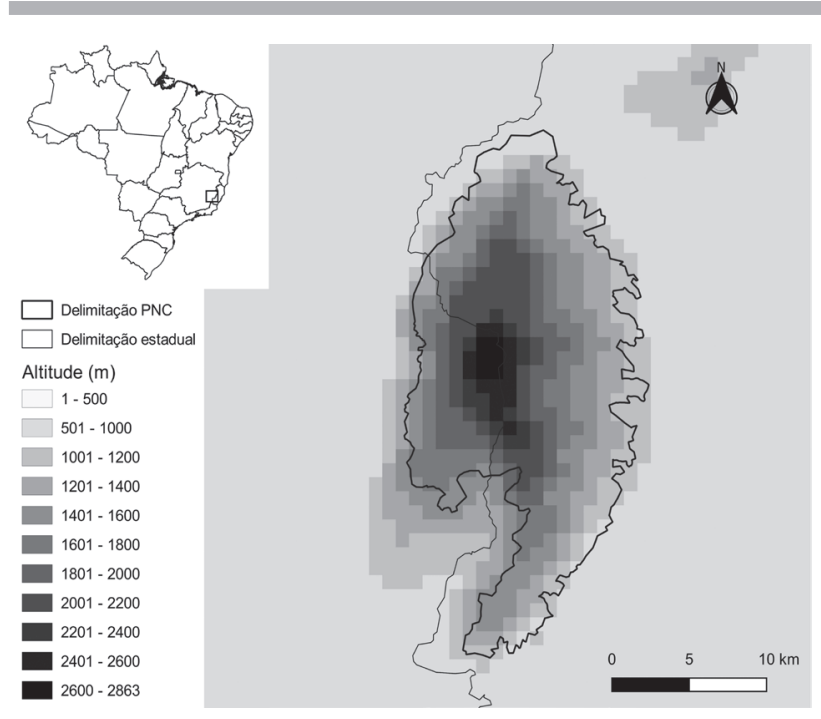

Figura 1- Mapa do Parque Nacional do Caparaó, Estados do Espírito Santo e Minais Gerais, Brasil.

Figure 1- Map of the Parque Nacional do Caparaó, States of Espírito Santo and Minas Gerais, Brazil.

do Parque). Possui atualmente uma área de 31.853 hectares e um amplo gradiente de altitude que varia de 997 a 2.890 m, sendo o Pico da Bandeira o ponto culminante, o terceiro mais alto do Brasil (ICMBio 2015).

A vegetação do PNC é caracterizada por diferentes fitofisionomias, as quais incluem formações de floresta ombrófila densa (montana e alto montana), floresta estacional semidecidual montana e campos de altitude. Também ocorrem ecossistemas ecotonais ou de transição (áreas de tensão) entre florestas e campo, bem como entre florestas e pastagens. O solo caracteriza-se por, no mínimo, nove classes e subtipos: Cambissolo Háplico Tb Distrófico, Cambissolo Háplico Tb Eutrófico, Nitossolo Vermelho Eutrófico, Neossolo Litólico, Neossolo Flúvico, Latossolo Vermelho-Amarelo Distrófico, Plintossolo Pétrico Concrecionário Distrófico, além de amplas manchas de exposições rochosas (ICMBio 2015).

Para o levantamento das espécies de Verbenaceae ocorrentes no PNC foram analisadas as coleções depositadas nos herbários CESJ, ESA, HUEMG, $\mathrm{K}, \mathrm{MBM}, \mathrm{NY}, \mathrm{RB}$ (que inclui atualmente a coleção do antigo herbário GFJP), SPF e VIES (acrônimos segundo Thiers 2019), além de expedições de coletas esporádicas realizadas na região entre os anos de 2014 e 2017. A identificação dos táxons foi realizada por meio de literatura especializada (Schauer 1847, Silva 1999, Atkins 2005, O’Leary 2007, Bueno \& Leonhardt 2011, Sanders 2012, O'Leary \& Thode 2016) e consulta aos tipos através do JSTOR (https://plants. jstor.org/). A terminologia morfológica segue Radford et al. (1974), Harris \& Harris (2003) e Gonçalves \& Lorenzi (2007). As informações sobre fenologia e habitat foram obtidas com base nas etiquetas de coleta dos espécimes e observações de campo.

\section{Resultados e Discussão}

Verbenaceae está representada no PNC por nove táxons distribuídos em cinco gêneros: Citharexylum solanaceum Cham., Glandularia lobata (Vell.) P.Peralta \& Thode, Lantana fucata Lindl., Lantana nivea Vent., Lantana robusta Schauer, Lantana sp., Lippia sp., Stachytarpheta cayennensis (Rich.) Vahl e Verbena rigida Spreng. Os representantes da família são encontrados na área de estudo em floresta ombrófila densa, campo de altitude, na transição entre floresta estacional semidecidual e o campo de altitude e floresta ciliar.

Dentre os nove táxons registrados, Lantana fucata e Stachytarpheta cayennensis são consideradas espécies ruderais (Lorenzi 1991). Segundo BFG (2018) Lantana nivea não apresenta registros para o país, embora Sanders (2012) indique a ocorrência desta espécie para a Bahia, Distrito Federal, Minas Gerais e Rio de Janeiro. Assim, através da análise minuciosa dos tipos nomenclaturais foi possível confirmar a ocorrência desta espécie para o Brasil, e seu primeiro registro para o Estado do Espírito Santo (Sanders 2012). Os táxons Lantana sp. e Lippia sp. apresentam um conjunto de caracteres únicos, sendo distintos das demais espécies conhecidas de Lantana L. e Lippia L. e, portanto, possivelmente tratam-se de espécies novas. Pelo visto estes táxons são endêmicos da Floresta Atlântica brasileira, e assim como Lantana robusta possuem distribuição mais restrita, merecendo atenção especial em planos de manejo e demais estratégias para a conservação da biodiversidade.

Em comparação a outras localidades da Serra da Mantiqueira, a riqueza de Verbenaceae no PNC é relevante, uma vez que quatro espécies foram registradas para a Reserva Biológica da Represa do Grama (Cardoso et al. 2017), cinco para a Serra Negra (Cardoso et al. 2018), oito para o Parque Estadual do Ibitipoca (Cruz \& Salimena 2017), nove no Parque Nacional do Itatiaia (Santiago et al. dados não publicados) e dez para o Parque Estadual da Serra do Papagaio (Cardoso et al. dados não publicados). As espécies ocorrentes no PNC compartilhadas com as áreas supracitadas são apresentadas na tabela 1 . De modo geral, poucas espécies de Verbenaceae 
Tabela 1. Comparação entre listagens de Verbenaceae da Serra da Mantiqueira (Brasil) e de espécies compartilhadas com o Parque Nacional do Caparaó.

Table 1. Comparison among lists of Verbenaceae of Serra da Mantiqueira (Brazil) and the shared species with the Parque Nacional do Caparaó.

\begin{tabular}{|c|c|c|c|}
\hline Área & Tamanho da área & Total de espécies & $\begin{array}{c}\text { Espécies compartilhadas com } \\
\text { PNC }\end{array}$ \\
\hline $\begin{array}{l}\text { Reserva Biológica da Represa do Grama } \\
\text { (Cardoso et al. 2017) }\end{array}$ & 263,8 ha & 4 & L. fucata e $S$. cayennensis \\
\hline Serra Negra (Cardoso et al. 2018) & 10.000 ha & 5 & L. fucata e $V$. rigida \\
\hline P.E. Ibitipoca (Cruz \& Salimena 2017) & $1.923,5$ ha & 8 & L. fucata \\
\hline $\begin{array}{l}\text { P.N. Itatiaia (Santiago et al. dados não } \\
\text { publicados) }\end{array}$ & 30.000 ha & 9 & $\begin{array}{l}\text { G. lobata, L. fucata. S. } \\
\text { cayennensis e V. rigida }\end{array}$ \\
\hline $\begin{array}{l}\text { P.E. Serra do Papagaio (Cardoso et al. } \\
\text { dados não publicados) }\end{array}$ & 22.917 ha & 10 & G. lobata e L. fucata \\
\hline
\end{tabular}

são compartilhadas entre as áreas já estudadas da Serra da Mantiqueira, sendo comum entre elas praticamente apenas as espécies ruderais. Desta forma, é possível constatar que neste complexo de montanhas algumas espécies apresentam distribuição restrita microendêmica, e mesmo àquelas com ampla distribuição não são encontradas nas diferentes áreas da Serra da Mantiqueira (Cardoso et al. 2017, Cardoso et al. 2018, Cardoso et al. dados não publicados, Cruz \& Salimena 2017, Santiago et al. dados não publicados).

Chave de Identificação para as espécies de Verbenaceae do Parque Nacional do Caparaó

1. Folhas com par de glândulas conspícuo próximo ao pecíolo, margem inteira; flores pediceladas; cálice cupuliforme

Citharexylum solanaceum

1. Folhas sem par de glândulas, margem crenada ou serreada; flores sésseis; cálice tubuloso

2. Cálice imerso nas escavações da raque; androceu com 2 estames férteis e 2 estaminódios

Stachytarpheta cayennensis

2. Cálice não imerso na raque; androceu com 4 estames férteis

3. Inflorescências terminais, dispostas de forma trímera ou tetrâmera; profilos presentes; corola 5-lobada

4. Folhas pecioladas, face adaxial estrigosa; brácteas menores que o cálice; par superior de estames com apêndices conectivais Glandularia lobata

4. Folhas sésseis, face adaxial híspida; brácteas maiores que o cálice; par superior de estames sem apêndices conectivais

Verbena rigida

3. Inflorescência 1-2-axila; profilos ausentes; corola 2-labiada

5. Ramos inermes; brácteas desiguais (2 externas maiores que as internas)

6. Ramos adultos cilíndricos, cicatrizes peciolares evidentes; brácteas estrigosas ao longo das nervuras, densamente glandulosas; cálice 2-laciniado; fruto esquizocarpo, formado por

2 mericarpos Lippia sp.

6. Ramos tetragonais quando adultos e jovens, sem cicatrizes peciolares; brácteas pubescentes ou vilosas, tricomas glandulares sésseis esparsos; cálice 4-laciniado; fruto drupa, formado por 1-pireno

7. Face adaxial da lâmina foliar estrigosa a esparsamente pubescente; brácteas externas largoovadas, internas ovadas, pubescentes Lantana fucata

7. Face adaxial da lâmina foliar hirsuta, brácteas externas e internas oblongas, vilosas Lantana robusta

5. Ramos aculeados; brácteas de tamanhos semelhantes

8. Tricomas glandulares pedicelados abundantes por toda a planta; folhas com ápice caudado; brácteas elípticas; corola vermelha, amarela ou alaranjada Lantana sp.

8. Tricomas glandulares pedicelados ausentes; folhas com ápice agudo-acuminado; brácteas estreito-lineares; corola lilás ou branca 
1. Citharexylum solanaceum Cham., Linnaea 7(1): 119. 1832.

Figura 2a-b

Árvores 5-7 m alt., ramos cilíndricos ou tetragonais, pubescentes, cicatrizes peciolares ausentes, inermes. Folhas opostas, pecioladas, lâmina 14-19 × 5,8-7,2 cm, cartácea, ovada, ápice agudo, base cuneada, par de glândulas conspícuo próximo ao pecíolo, margem inteira, face adaxial pubérula, face abaxial pubescente. Inflorescências $15-20 \mathrm{~cm}$ compr., terminais, solitárias, pedúnculo ca. $1,5 \mathrm{~cm}$ compr., pubescente, raque visível; profilos ausentes; brácteas diminutas, ca. $1 \mathrm{~mm}$ compr., lanceoladas, verdes, pubescentes. Flores pediceladas; cálice 4-6 mm compr., cupuliforme, não imerso na raque, 5-laciniado, verde, subcoriáceo, pubescente, não acrescente no fruto; corola 0,7-1,1 cm compr., 5-lobada, branca, glabra; estames 4 , inseridos na porção mediana do tubo da corola, apêndices conectivais ausentes, 1 estaminódio inserido na porção inferior; ovário ca. 1,5 mm compr., 2-carpelar, 2-locular, lóculos 1-ovulados. Fruto drupa, formado por 2 pirenos, 1,8-2,2 cm compr., imaturo verde, maduro vermelho, superfície externa lisa, imerso no cálice persistente.

Citharexylum solanaceum é encontrada na Argentina e no Brasil, onde ocorre nos Estados de Goiás, Minas Gerais, Rio de Janeiro, São Paulo, Santa Catarina, Paraná e Rio Grande do Sul (BFG 2018, O'Leary \& Keller 2018). Caracteriza-se por apresentar hábito arbóreo, ramos pubescentes; par de glândulas conspícuo na base da lâmina foliar; flores pediceladas; cálice cupuliforme, subcoriáceo, não acrescente no fruto; corola branca, 5-lobada e fruto drupáceo, quando maduro de coloração vermelha. No PNC é encontrada em floresta ombrófila densa e floresta estacional semidecidual. Coletada com frutos em fevereiro e março.

Material examinado: BRASIL. Minas GeraIs. Alto Caparaó, II-1996, L.S. Leoni 3232 (RB); 7-III-2010, G. Heringer et al. 340 (RB).

Material adicional examinado: BRASIL. ParanÁ. Guaraniaçu, 20-X-1975, G. Hatschbach 37348 (MBM); Guarapuava, 6-II-1968, G. Hatschbach \& O. Guimarães (MBM).

2. Glandularia lobata (Vell.) P.Peralta \& Thode, Rodriguésia 61(suppl.): 30. 2010.

Figura 2c-d

Herbáceas 20-60 cm alt., ramos tetragonais, hirsutos ou estrigosos, tricomas glandulares pedicelados presentes, cicatrizes peciolares ausentes, inermes. Folhas opostas, pecioladas, lâmina 1,3-4 × 1-2 cm, cartácea, oval-lanceolada a lanceolada, ápice agudo, base obtusa a truncada, decurrente, par de glândulas ausente próximo ao pecíolo, margem serreada, ciliada, face adaxial estrigosa, face abaxial pubescente ao longo das nervuras. Inflorescências 1,2-2,2 cm compr., terminais, dispostas de forma trímera ou tetrâmera, pedúnculo 2-4 cm compr., tricomas glandulares pedicelados presentes; profilos presentes; brácteas 2-3,5 mm compr., ovadas a lanceoladas, verdes, pubescentes, margem ciliada. Flores sésseis; cálice 4-5 mm compr., tubuloso, não imerso na raque, 5-laciniado, verde-arroxeado, membranáceo, esparsamente pubescente, acrescente no fruto; corola 5,2-6 mm compr., 5-lobada, lilás, pubescente; estames 4, inseridos na porção superior do tubo da corola, didínamos, par superior com apêndices conectivais; ovário ca. $1 \mathrm{~mm}$ compr., 2-carpelar, 4-locular, lóculos 1 -ovulados. Fruto esquizocarpo, formado por 4 mericarpos, 2-2,7 mm compr., castanho, superfície externa reticulada, envolto pelo cálice persistente.

Glandularia lobata distribui-se nas regiões leste do Paraguai, nordeste da Argentina e nas regiões Sul e Sudeste do Brasil, na Floresta Atlântica e Pampa (O’Leary \& Thode 2016, BFG 2018). Distingue-se por apresentar lâmina foliar com base obtusa a truncada, margem inciso-serreada; inflorescências dispostas de forma trímera ou tetrâmera, brácteas menores que o cálice, corola 5-lobada, lilás, e par superior de estames com apêndices conectivais. No PNC é encontrada em campo de altitude, na transição da floresta estacional semidecidual com o campo de altitude e floresta ciliar. Coletada com flores e frutos em fevereiro, março, agosto, outubro, novembro e dezembro.

Material examinado: BRASIL. EsPírito SANTO: Dores de Rio Preto, 20-VIII-2012, T.B. Flores et al. 1336 (ESA, RB); Iúna, 20-IX-2012, A.V. Scatigna et al. 259 (UEC); Pico da Bandeira, 3-III-1959, H.S. Irwin 2783 (NY). Minas Gerais: 30-X-1922, P.C. Porto 1147 (NY, RB); X-1941, Brade 17087 (RB); 20-II-1988, L. Krieger s.n. (CESJ 23215); 19-III-1988, R.F. Novelino et al. s.n. (CESJ 22229); 19-XI-1988, L. Krieger s.n. (CESJ 24102); Alto Caparaó, 29-IX-95, J.A. Lombardi 941 (BHCB, CESJ); 12-X-1992, L.S. Leoni 1972 (RB); 12-X-2000, L.S. Leoni 4508 (CESJ), 23-II-2000, V.C. Souza 23233 (ESA); VIII-2001, V.C. Souza 26981 (ESA). Alto Jequitibá, 3-XII-2010, A.K.L. Venda 46 (BHCB). Espera Feliz, 20-IX-2016, C.D.M. Ferreira et al. 343 (RB); 10-X-1999, W. Foster et al. 109 (ESA). 
3. Lantana fucata Lindl., Bot. Reg. 10: t. 798. 1824. Figura 2e-f

Arbustos 0,5-1,6 m alt., ramos tetragonais, estrigosos a pubescentes, tricomas glandulares sésseis presentes, cicatrizes peciolares ausentes, inermes. Folhas opostas, pecioladas, lâmina 1,4-6 × 1-3,2 cm, cartácea, ovada ou elíptica, ápice agudo a obtuso, base truncada, cuneada ou atenuada, par de glândulas ausente próximo ao pecíolo, margem serreada, ciliada, face adaxial estrigosa a esparsamente pubescente, tricomas glandulares sésseis presentes, face abaxial esparsamente pubescente a tomentosa, tricomas concentrados ao longo das nervuras, tricomas glandulares sésseis presentes. Inflorescências 1-1,5 cm compr., 1-axila, pedúnculo 1,3-4,7 cm compr., pubescente, tricomas glandulares sésseis presentes; profilos ausentes; brácteas desiguais, externas 0,6-1 cm compr., largo-ovadas, internas 3,2-4,6 mm compr., ovadas, verdes, pubescentes, tricomas glandulares sésseis presentes, margem ciliada; cálice 1,9-2,1 mm compr., tubuloso, não imerso na raque, 4-laciniado, verde, membranáceo, seríceo, acrescente
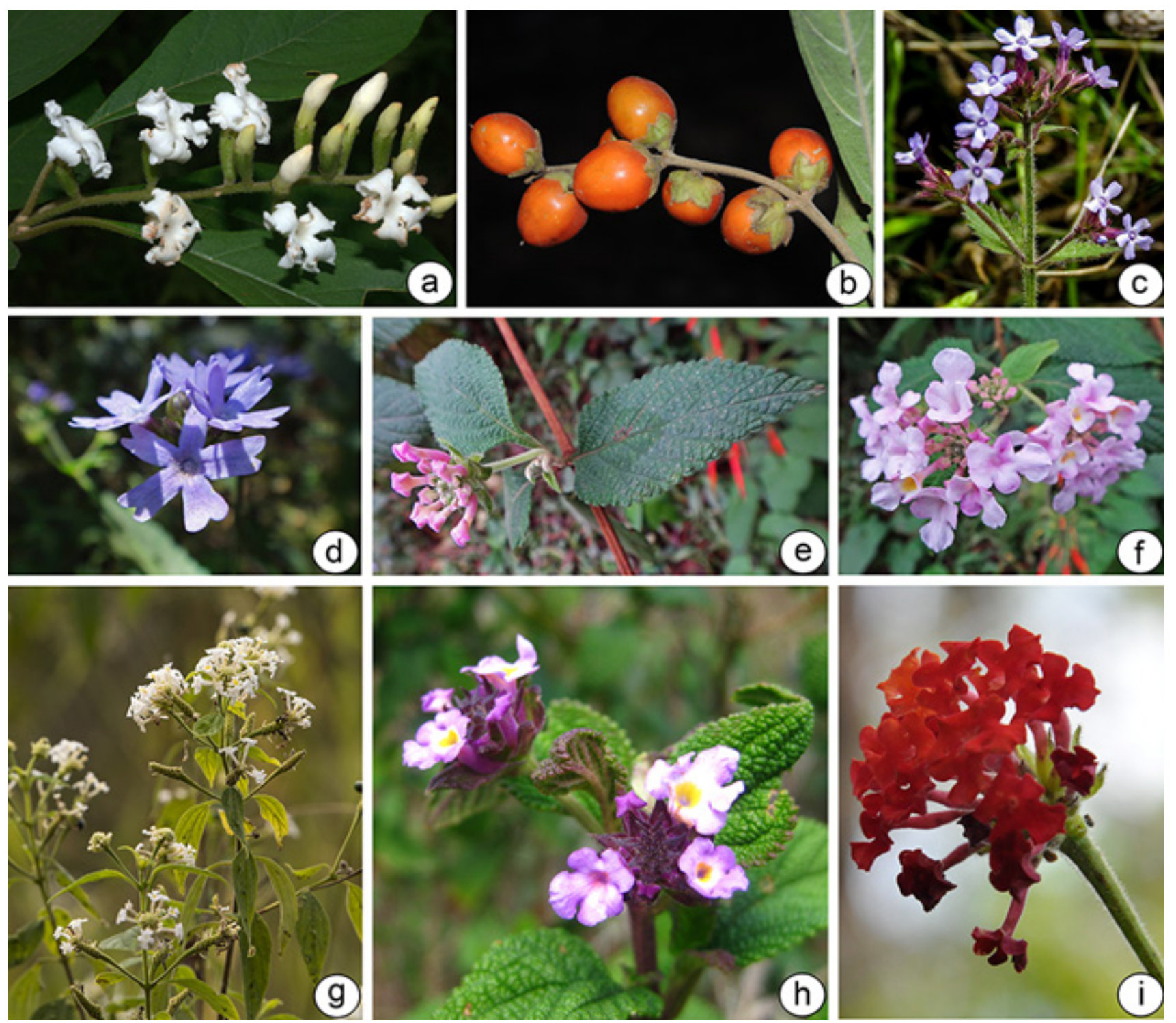

Figura 2. Espécies de Verbenaceae do Parque Nacional do Caparaó, Brasil. a-b. Citharexylum solanaceum. c-d. Glandularia lobata. e-f. Lantana fucata. g. Lantana nivea. h. Lantana robusta. i. Lantana sp. (fotos a-b: Sergio Bordignon; c-f: Rodrigo Penati; g: Pedro H. Nobre; h: Vinícius Dittrich; i: Pedro Cardoso).

Figure 2. Species of Verbenaceae from the Parque Nacional do Caparaó, Brazil. a-b. Citharexylum solanaceum. c-d. Glandularia lobata. e-f. Lantana fucata. g. Lantana nivea. h. Lantana robusta. i. Lantana sp. (photos a-b: Sergio Bordignon; c-f: Rodrigo Penati; g: Pedro H. Nobre; h: Vinícius Dittrich; i: Pedro Cardoso). 
no fruto; corola 0,6-1 cm compr., 2-labiada, lilás, pubescente, tricomas glandulares sésseis presentes, fauce amarela, estames 4 , inseridos na metade do tubo da corola, didínamos, apêndices conectivais ausentes; ovário 0,5-1 mm compr., 1-carpelar, 2-locular, lóculos 1-ovulados. Fruto drupa, formado por 1-mericarpo, 2,5-2,8 mm compr., imaturos verdes, maduros negros, superfície externa lisa, envolto pelo cálice persistente.

Lantana fucata possui ampla distribuição nas regiões temperadas, subtropicais e tropicais das Américas e foi introduzida em outras regiões do globo, como Índia e África (Silva 1999). No Brasil, ocorre nas regiões Nordeste, Centro-Oeste, Sudeste e Sul (BFG 2018). Caracteriza-se por apresentar ramos inermes, estrigosos a pubescentes; brácteas desiguais, sendo as externas largo-ovadas e as internas ovadas; cálice 4-laciniado, seríceo e corola lilás com fauce amarela. No PNC é encontrada em bordas de trilhas e próxima a cursos d'água. Coletada com flores e frutos em agosto, setembro, outubro e dezembro.

Material examinado: BRASIL. Minas Gerais. 17-IX-1941, Brade 16957 (NY, RB, SPF); Vale Verde, 18-XII-1988, L. Krieger et al. s.n. (SPF 113281a); XII-1989, S.M.S. Verardo et al. s.n. (CESJ 23260, SPF66729, SPF 113291); Espera Feliz, 19-X-1999, $W$. Foster et al. 103 (RB). EsPírito SANTO. Dores do Rio Preto, 14-IX-2017, I.T.F.V. Lopes \& L.S. Ribeiro 249 (HUEMG); Ibitirama, 17-IX-2012, J.P.F. Zorzanelli et al. 545 (VIES); Iúna, 4-VIII-2016, F.R.G. Salimena \& P.H. Nobre 3974 (CESJ).

4. Lantana nivea Vent., Jard. Malmaison 8, t. 8. 1805. Figura $2 g$

Arbusto 2-3 m alt., ramos marcadamente tetragonais, pubescentes a hirsutos, tricomas glandulares sésseis presentes, cicatrizes peciolares ausentes, aculeados. Folhas opostas, pecioladas, lâmina 6-9 × 2-4,1 cm, cartácea, lanceoladas ou elípticas, ápice agudo-acuminado, base cuneada, par de glândulas ausente próximo ao pecíolo, margem serreada, ciliada, face adaxial escabra, tricomas glandulares sésseis presentes, face abaxial hirsuta, tricomas concentrados ao longo das nervuras, tricomas glandulares sésseis presentes. Inflorescências 1,3-2 cm compr., 1-2-axila, pedúnculo 3-5,3 cm compr., hirsuto, tricomas glandulares sésseis abundantes; profilos ausentes; brácteas iguais, 3-6 mm compr., estreitolineares, verdes, estrigoso-canescentes, tricomas glandulares sésseis presentes, margem ciliada. Flores sésseis; cálice 3-3,2 mm compr., tubuloso, não imerso na raque, verde, membranáceo, densamente hirsuto, tricomas glandulares sésseis presentes, não acrescente no fruto; corola 0,9-1,1 cm compr., 2-labiada, lilás ou branca, pubescente externamente, tricomas glandulares sésseis presentes, fauce amarela, estames 4, inseridos na metade do tubo da corola, didínamos; apêndices conectivais ausentes; ovário $0,5-0,6 \mathrm{~mm}$ compr., 1-carpelar, 2-locular, lóculos 1-ovulados. Fruto drupa, formado por 1-pireno, 4,5-4,7 mm compr., imaturo verde, maduro roxo, superfície externa lisa.

Lantana nivea é uma espécie nativa do Brasil, com registros para a Bahia, Distrito Federal, Minas Gerais e Rio de Janeiro, e cultivada no México e Austrália (Sanders 2012). Caracteriza-se pelo hábito muito ramificado; ramos marcadamente tetragonais, aculeados; folhas lanceoladas ou elípticas, ápice agudo-acuminado, base cuneada, face adaxial escabra; brácteas lineares, estrigoso-canescentes e corola lilás ou branca. No PNC é encontrada em floresta ciliar somente na porção capixaba, constituindo um novo registro para a flora do Espírito Santo. Coletada com flores e frutos em janeiro e agosto.

Material examinado: BRASIL. EsPíRITo SANTO. Iúna, 4-VIII-2016, F.R.G. Salimena \& P.H. Nobre 3975 (CESJ); 4-VIII-2016, F.R.G. Salimena \& P.H. Nobre 3976 (CESJ).

Material adicional examinado: EsPírito SANTo. Castelo, Parque Estadual do Forno Grande, 21-IX-2018, P.H. Cardoso et al. 44 (CESJ); MinAS GeraIs. Viçosa, 9-III-1930, Y. Mexia $4448 a$ (S); Araponga, 18-XI-1958, H.S. Irwin 2112 (NY). BAHIA. Camacã,14-VII-1978, Santos \& Mattos 3304 (NY).

5. Lantana robusta Schauer, Prodr. [A. P. de Candolle] 11: 601. 1847.

Figura $2 \mathrm{~h}$

Arbustos 1-1,5 m alt., ramos tetragonais, hirsutos, cicatrizes peciolares ausentes, inermes. Folhas opostas, pecioladas, lâmina 4,4-7,5 × 1,8-3 cm, cartácea, ovada, ápice agudo, base cuneada, par de glândulas ausente próximo ao pecíolo, margem serreada, ciliada, face adaxial hirsuta, face abaxial hirsuta, tricomas glandulares sésseis presentes. Inflorescências 0,9-1,2 cm compr., 1-2-axila, pedúnculo 1,7-4,2 cm compr., hirsuto, tricomas glandulares sésseis presentes; profilos ausentes; brácteas desiguais, externas 7-8 $\mathrm{mm}$ compr., internas 4,7-5,2 mm compr., oblongas, vináceas, vilosas, tricomas glandulares sésseis presentes, margem ciliada; cálice 2,8-3 mm compr., 
tubuloso, não imerso na raque, 4-laciniado, verde, membranáceo, viloso, acrescente no fruto; corola 0,7-1 cm compr., 2-labiada, lilás, pubescente, tricomas glandulares sésseis presentes, fauce amarela, estames 4, inseridos na metade do tubo da corola, didínamos, apêndices conectivais ausentes; ovário ca. 0,5 mm compr., 1-carpelar, 2-locular, lóculos 1-ovulados. Fruto drupa, formado por 1-pireno, 2,5-2,8 mm compr., imaturo verde, maduro vináceo, superfície externa lisa, envolto pelo cálice persistente.

Lantana robusta é endêmica do Brasil, encontrada na Floresta Atlântica, Estados de Minas Gerais e Rio de Janeiro (Silva 1999, BFG 2018). Caracteriza-se por apresentar ramos inermes, hirsutos; lâmina foliar hirsuta, com indumento mais denso na face abaxial; brácteas oblongas, vináceas, as externas maiores que as internas; cálice 4-laciniado e corola lilás com fauce amarela. No PNC é encontrada em floresta estacional semidecidual. Coletada com flores e frutos em janeiro, fevereiro, outubro e dezembro.

Material examinado: BRASIL. Minas Gerais. X-1941, Brade 17086 (NY, RB). Alto Caparaó, 10-II-1973, G. Hatschbach \& Z. Ahumada 31417 (MBM, NY), 23-I-2008, B.V. Tinti et al. 474 (HUEMG); 28-IV-2015. W.O. Souza 410 (VIES); Vale Verde, 18-XII-1988, L. Krieger et al. s.n. (CESJ 23308, SPF 66728, SPF 113281b). São Domingos, 13-I-2010, G.D. Colletta \& T.B. Flores 365 (RB).

Material adicional examinado: BRASIL. RIO DE JANEIRO. Santa Maria Madalena, 18-VI-2004, L.G.T. Temponi 364 et al. (SPF); Teresópolis, 10-II-1968, D. Sucre \& P.I.S. Braga 2339 (SPF).

\section{Lantana sp.}

Figuraa 2i, 3a

Arbustos 2-3 m alt., ramos tetragonais, tricomas glandulares pedicelados abundantes, cicatrizes peciolares ausentes, aculeados. Folhas opostas, pecioladas, lâmina 5,3-10 × 2,3-5 cm, cartácea, lanceolada ou elíptica, ápice caudado, base cuneada ou arredondada, par de glândulas ausente próximo ao pecíolo, margem serreada, ciliada, face adaxial densamente estrigosa, tricomas glandulares pedicelados abundantes, face abaxial hirsuta, tricomas glandulares pedicelados abundantes. Inflorescências $1-1,7 \mathrm{~cm}$ compr., 1-axila, pedúnculo $(-4,5) 6,5-12 \mathrm{~cm}$ compr., tricomas glandulares abundantes; profilos ausentes; brácteas iguais, 5-7 mm compr., elípticas, verdes, hirsutas, tricomas glandulares pedicelados abundantes, margem ciliada. Flores sésseis; cálice
1,8-2 mm compr., tubuloso, não imerso na raque, 2-laciniado, verde, hirsuto, densamente coberto por tricomas glandulares pedicelados, ciliado, não acrescente no fruto; corola 1-1,2 cm compr., 2-labiada, vermelha, alaranjada, amarela, densamente pubescente, tricomas glandulares sésseis e pedicelados presentes, estames 4 , inseridos na metade do tubo da corola, didínamos, apêndices conectivais ausentes; ovário ca. $1 \mathrm{~mm}$ compr., 1-carpelar, 2-locular, lóculos 1-ovulados. Fruto drupa, formado por 1-pireno, ca. 4,5 mm compr., imaturo verde, maduro negro, superfície externa lisa.

Lantana sp. é distinta por apresentar tricomas glandulares pedicelados por toda planta; folhas lanceoladas ou elípticas, ápice caudado, base cuneada ou arredondada; pedúnculos frequentemente maiores que as folhas; brácteas elípticas e corola amarela, vermelha ou alaranjada. É morfologicamente próxima a L. camara L. e a L. tillifolia Cham., mas estes caracteres em conjunto não permitem sua identificação como nenhuma espécie já descrita para o gênero. A correta identificação deste táxon demanda uma avaliação mais cuidadosa, na busca de outras coleções, tratando-se possivelmente de uma espécie inédita. No PNC é encontrada em floresta estacional semidecidual. Coletada com flores e frutos em fevereiro e abril.

Material examinado: BRASIL. Minas GeraIs. Alto Caparaó, 10-II-1973, G. Hatschbach \& Z. Ahumada 31444 (K, MBM); 22-IV-2006, B.V. Tinti et al. 221 (HUEMG).

\section{Lippia sp.}

Figura 3b-c

Arbustos 0,5-1,6 m de alt., ramos jovens tetragonais, estrigosos, tricomas glandulares sésseis presentes, ramos adultos cilíndricos, glabrescentes, cicatrizes peciolares evidentes, inermes. Folhas opostas, pecioladas, lâmina 1,5-3 × 0,7-2 cm, cartácea, ovada, oval-elíptica ou obovada, ápice agudo, obtuso a arredondado, base cuneada, par de glândulas ausente próximo ao pecíolo, margem crenado-serreada, ciliada, face adaxial esparsamente estrigosa, densamente coberta por tricomas glandulares sésseis, face abaxial estrigosa ao longo das nervuras, densamente coberta por tricomas glandulares sésseis. Inflorescências 0,9-1,5 cm compr., 1-axila, pedúnculo 2-5,5 cm compr., estrigoso, tricomas glandulares sésseis presentes; profilos ausentes; brácteas desiguais, externas 6,5-8 $\mathrm{mm}$ compr., oblongo-elípticas, internas 4-5,7 mm compr., lanceoladas, verdes, estrigosas ao longo das nervuras, 
densamente cobertas de tricomas glandulares sésseis, margem ciliada. Flores sésseis; cálice 1,7-2,2 mm compr., tubuloso, emerso na raque, 2-laciniado, verde, membranáceo, externamente hirsuto, tricomas glandulares sésseis presentes, acrescente no fruto; corola 1,1-1,3 cm compr., 2-labiada, lilás, pubescente, tricomas glandulares sésseis presentes, fauce amarela, estames 4, inseridos na metade do tubo da corola, didínamos, apêndices conectivais ausentes; ovário ca. $2 \mathrm{~mm}$ compr., 2-locular, lóculos 1-seminado. Fruto esquizocarpo, formado por 2-mericarpos, 1,8-2 mm compr., castanho, superfície externa lisa, envolto pelo cálice persistente.

Lippia sp. é o único táxon do gênero encontrado no PNC. Caracteriza-se por apresentar ramos jovens tetragonais, densamente estrigosos, tricomas glandulares sésseis presentes, ramos adultos glabrescentes, cicatrizes peciolares evidentes; folhas pecioladas, lâmina ovada, oval-elíptica ou obovada, base cuneada, densamente coberta por tricomas glandulares sésseis em ambas as faces e brácteas desiguais, sendo as externas oblongoelípticas e as internas lanceoladas. É morfologicamente semelhante à Lippia triplinervis Schauer, no entanto, os caracteres supracitados em conjunto não permitem sua identificação como nenhuma espécie já descrita para o gênero. A correta identificação deste táxon também demanda uma avaliação mais cuidadosa, e provavelmente trata-se de uma espécie inédita, aparentemente endêmica da Serra da Mantiqueira. No PNC só foi encontrada até o momento em campo de altitude. Coletada com flores e frutos em abril, junho, julho, setembro e outubro.
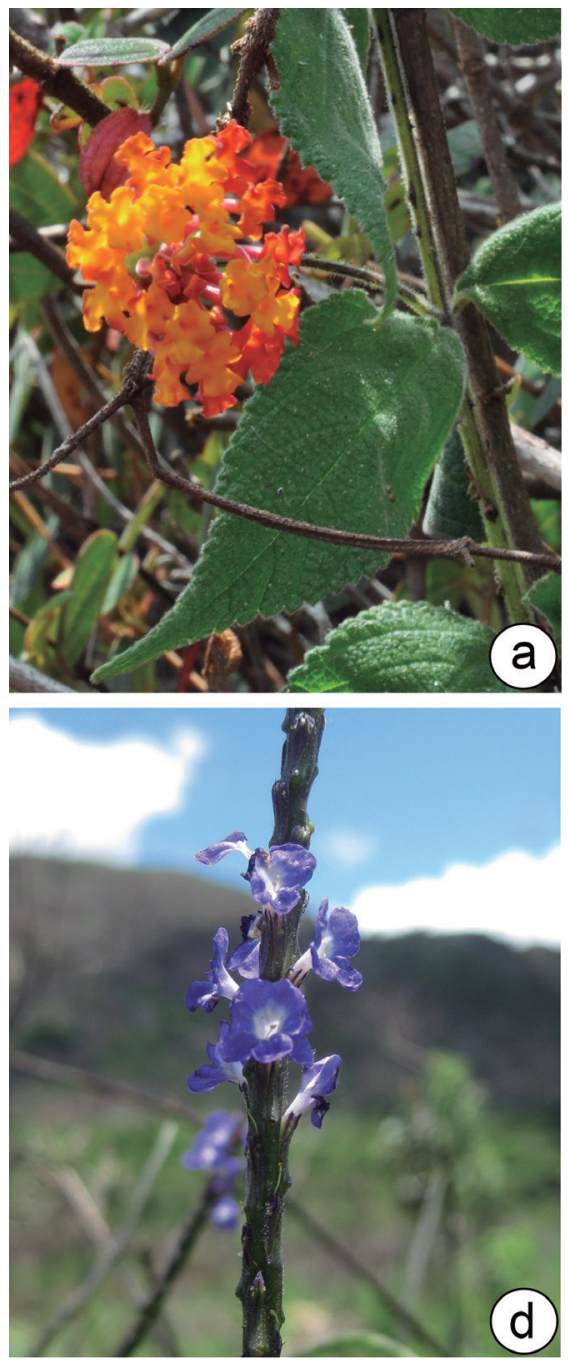
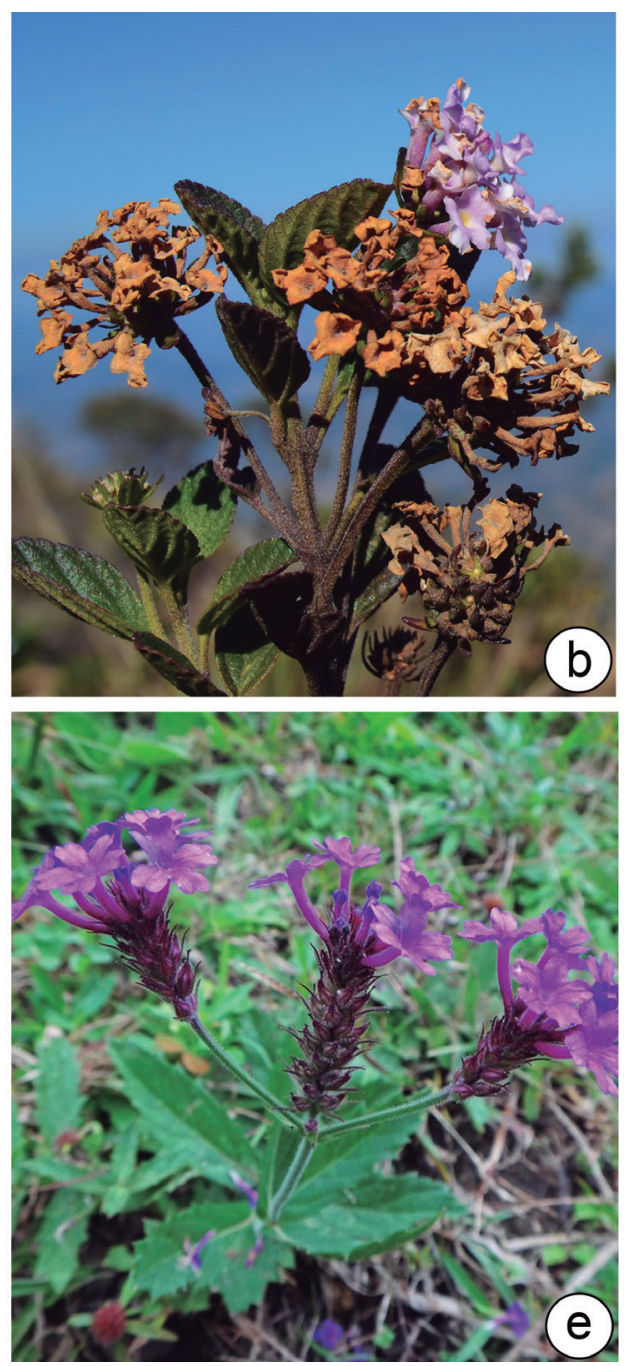
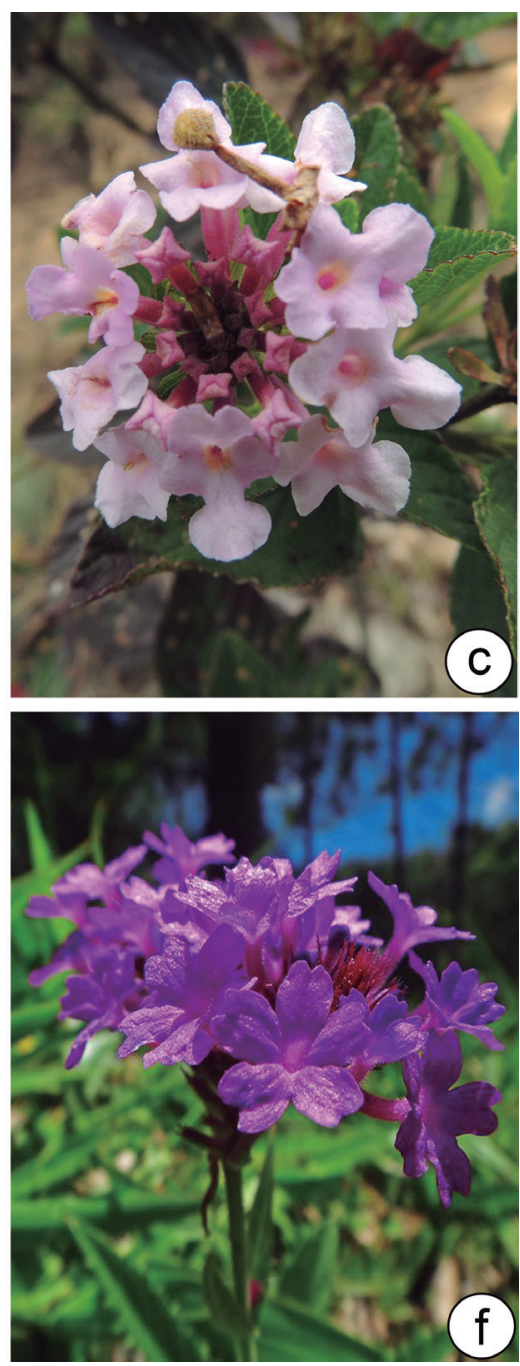

Figura 3- Espécies de Verbenaceae do Parque Nacional do Caparaó, Brasil. a. Lantana sp. b-c. Lippia sp. d. Stachytarpheta cayennensis. e-f. Verbena rigida. (fotos a: Pedro Cardoso; b: Samyra Furtado; c: Ludymila Cruz; d: Vinícius Dittrich; e-f: Rodrigo Penati).

Figure 3- Species of Verbenaceae from the Parque Nacional do Caparaó, Brazil. a. Lantana sp. b-c. Lippia sp. d. Stachytarpheta cayennensis. e-f. Verbena rigida. (photos a: Pedro Cardoso; b: Samyra Furtado; c: Ludymila Cruz; d: Vinícius Dittrich; e-f: Rodrigo Penati). 
Material examinado: BRASIL. Minas Gerais. 5-VIII-1990, L.S. Leoni et al. s.n. (RB 731473); Alto Caparaó, 4-VIII-2016, F.R.G. Salimena \& P.H. Nobre 3977 (CESJ); Serra do Caparaó, 19-VII-1988, F.R.N. Camargo et al. 9 (CESJ, SPF); 1-IV-1989, L. Krieger s.n. (CESJ 23562, SPF 66730); Vale Encantado, 14VI-1991, fl., G. Hatschbach \& O. Guimarães 55492 (CESJ, MBM); 2-IX-1996. V.C. Souza et al. 12178 (ESA, RB); 31-VIII-2017, L.C. Pereira et al. 55 (CESJ).

8. Stachytarpheta cayennensis (Rich.) Vahl, Enum. P1. 1 : 208. 1804.

Figura $3 d$

Herbáceas 0,5-1 m alt., ramos tetragonais, lateralmente pubescentes em duas faces opostas, glabrescente nas outras duas, cicatrizes peciolares ausentes, inermes. Folhas opostas, pecioladas, lâmina 2,6-5,5 × 1,3-3 cm, cartácea, ovada, ápice agudo, base atenuada, decorrente, par de glândulas ausente próximo ao pecíolo, nectários evidentes na porção basal, margem crenado-serreada, ciliada, face adaxial pubérula a pubescente, face abaxial pubescente. Inflorescências 9-25 cm compr., terminais, solitárias, pedúnculo inconspícuo, raque escavada; profilos ausentes; brácteas 3-5 mm compr., lanceoladas, verdes, pubérulas, margem ciliada. Flores sésseis; cálice 3-5,3 mm compr., tubuloso, imerso nas escavações da raque, 4-laciniado, seio adaxial presente, verde, membranáceo, esparsamente pubescente, acrescente no fruto; corola 5-7,5 mm compr., 5-lobada, lilás, glabra; estames 2, inseridos na porção mediana do tubo da corola, estaminódios 2 , apêndices conectivais ausentes; ovário ca. $1 \mathrm{~mm}$ compr., 2-carpelar, 2-locular, lóculos 1-ovulados. Fruto esquizocarpo, formado por 2 mericarpos, ca. 3,5 mm compr., castanho, superfície externa reticulada, envolto pelo cálice persistente.

Stachytarpheta cayennensis está amplamente distribuída na América Central e América do Sul e em todas as regiões do Brasil (Aktins 2005, BFG 2018). Pode ser reconhecida por apresentar lâmina foliar com nectários evidentes na porção basal; inflorescência terminal, cálice 4-laciniado com um seio adaxial longo, imerso nas escavações da raque e androceu com dois estames férteis e dois estaminódios. No PNC é encontrada em bordas de trilha. Coletada com flores e frutos em novembro.

Material examinado: BRASIL. Minas Gerais. I 20-XI-1988, L. Krieger et al. s.n. (CESJ 23978, SPF 66731). EsPírito SAnto. Divino de São Lourenço, 2007, T. Chimalli s.n. (CESJ 65364, VIES 27816).
9. Verbena rigida Spreng., Syst. veg. ed. 16, 4 (2): 230. 1827.

Figura $3 \mathrm{e}-\mathrm{f}$

Herbáceas 20-35 cm alt., ramos tetragonais, híspidos, tricomas glandulares pedicelados presentes, cicatrizes peciolares ausentes, inermes. Folhas opostas, sésseis, lâmina 2,3-4 × 0,7-1,2 cm, cartácea, elíptica a oblongo-elíptica, ápice agudo, base truncada, par de glândulas ausente, margem inciso-serrada, ciliada, face adaxial híspida, tricomas glandulares pedicelados presentes, face abaxial híspida, tricomas concentrados ao longo das nervuras. Inflorescências 1-3 cm compr., terminais, dispostas de forma trímers, pedúnculo 0,5-2 cm compr., hirsuto, tricomas glandulares pedicelados presentes; profilos presentes; brácteas 4,5-5,2 mm compr., estreito-ovadas, verdes, híspidas, tricomas glandulares pedicelados presentes, margem ciliada. Flores sésseis; cálice 3-3,5 mm compr., tubuloso, não imerso na raque, 5-laciniado, verde, membranáceo, híspido, tricomas glandulares pedicelados presentes, acrescente no fruto; corola 1-1,2 cm compr., 5-lobada, roxa, hirsuta; estames 4 , inseridos no terço inferior do tubo corola, didínamos, apêndices conectivais ausentes; ovário ca. 1,5 mm compr., 2-carpelar, 4-locular, lóculos 1-ovulados. Fruto esquizocarpo, formado por 4 mericarpos, ca. 2,5 mm compr., castanho, superfície externa reticulada, envolto pelo cálice persistente.

Verbena rigida é nativa do Paraguai, Bolívia, Uruguai, Argentina e Brasil, nas regiões Sul e Sudeste. Está naturalizada no restante da América, em parte da Europa, África do Sul, leste da Ásia e Austrália (O'Leary et al. 2007; BFG 2018). Caracteriza-se por apresentar ramos híspidos; folhas sésseis, com margem inciso-serrada; inflorescência disposta de forma trímera, brácteas maiores que o cálice e corola de 1-1,2 cm compr., 5-lobada, roxa. No PNC ocorre em campo de altitude. Coletada com flores e frutos em outubro.

Material examinado: BRASIL. EsPíRITO SANTO. Dores do Rio Preto, 21-X-2012, T.B. Flores et al. 1399 (ESA); 22-X-2012, T.B. Flores et al. 1415 (MBML, RB, UEC).

\section{Agradecimentos}

Os autores agradecem a Sergio Bordignon, Rodrigo Penati, Pedro H. Nobre, Vinícius Dittrich, Samyra Furtado e Ludymila Cruz a cessão das fotografias. O presente trabalho foi realizado com 
apoio da Coordenação de Aperfeiçoamento de Pessoal de Nível Superior - Brasil (CAPES) - Código de Financiamento 001.

\section{Literatura Citada}

Atkins, S. 1995. Verbenaceae. In: B.L. Stannard (ed.) Flora of the Pico das Almas. Royal Botanic Gardens, Kew. pp. 621-630.

Atkins, S. 2004. Verbenaceae. In: K. Kubtzki \& J.W. Kadereit (eds.). The Families and Genera of Vascular Plants. Springer-Verlag 7: 449-468.

Atkins, S. 2005. The genus Stachytarpheta (Verbenaceae) in Brazil. Kew Bulletin 60: 161-272.

BFG (The Brazil Flora Group). (2018) Brazilian Flora 2020: Innovation and collaboration to meet Target 1 of the Global Strategy for Plant Conservation (GSPC). Rodriguésia 69: 1513-1527.

Bueno, O. L., \& Leonhardt, C. 2011. Distribuição e potencial paisagístico dos gêneros Citharexylum L. e Verbenoxylum Tronc. no Rio Grande do Sul, Brasil. Iheringia. Série Botânica 66: 47-60.

Cantino, P.D. 1992a. Toward a phylogenetic classification of the Labiatae. In: R.M. Harley \& T. Reynolds (eds.). Advances in Labiatae. Science pp. 27-37.

Cantino, P.D. 1992b. Evidence for a polyphyletic origin of the Labiatae. Annals of the Missouri Botanical Garden 79: 361-379.

Cantino, P.D., Harley, R.M., Wagstaff, S.J. 1992. Genera of Labiatae: status and classification. In: R.M. Harley, T. Reynolds (eds.). Advances in Labiatae. Science 511-522.

Cardoso, P.H., Cabral, A., Tavares-Silva, P., \& SantosSilva, F. 2017. Verbenaceae na Reserva Biológica da Represa do Grama, Descoberto, Minas Gerais, Brasil. Holos Environment 17: 232-238.

Cardoso, P.H., Cabral, A., Valério, V.I.R. \& Salimena, F.R.G. 2018a. Verbenaceae na Serra Negra, Minas Gerais, Brasil. Rodriguésia 69: 777-786.

Cardoso, P.H., O'Leary, N., \& Salimena, F.R.G. 2018 b. Flora das cangas da Serra dos Carajás, Pará, Brasil: Verbenaceae. Rodriguésia 69: 1397-1403.

Cruz, L.V.V. \& Salimena, F.R.G. 2017. Verbenaceae J.St.Hil. do Parque Estadual do Ibitipoca, Minas Gerais, Brasil. Boletim de Botânica da Universidade de São Paulo 35: 65-74.

Faria, C.A., Romero, R. \& Leoni, L. 2006. Flora fanerogâmica do Parque Nacional do Caparaó: Melastomataceae. Pabstia 17: 1-31.

Feliciano, C.D., Savassi-Coutinho, A.P. \& Souza, V.C. 2010. Flora Fanerogâmica do Parque Nacional do Caparaó: Begoniaceae. Pabstia 21: 4-20.

Forster, W. \& Souza, V.C. 2013. Laeliinae (Orchidaceae) do Parque Nacional do Caparaó, Estados do Espírito Santo e Minas Gerais, Brasil. Hoehnea 40: 701-726.
Gonçalves, E.G. \& Lorenzi, H. 2007. Morfologia vegetal: organografia e dicionário ilustrado de morfologia das plantas vasculares. Instituto Plantarum, Nova Odessa.

Gonzaga, D.R. \& Menini Neto, L. 2017. Estado de conservação da Serra da Mantiqueira: ameaças, lacunas, avanços e perspectivas do conhecimento da flora. In: B.C. Barbosa, L.O. Resende, F. Prezoto \& E.L. Gonçalves (eds.). Tópicos em sustentabilidade e conservação. 1 ed. Real Consultoria em Negócios Ltda, Juiz de Fora, pp. 77-86.

Harley, R.M. \& Simmons, N.A. 1986. Florula of Mucugê, Chapada Diamantina, Bahia, Brasil. A descriptive check-list of the campo rupestre area. Royal Botanical Gardens, Kew.

Harris, J.G. \& Harris, M.W. 2003. Plant identification terminology: an illustrated glossary. 2ed. Spring Lake Publ., Spring Lake.

ICMBio (Instituto Chico Mendes de Conservação da Biodiversidade). 2015. Plano de Manejo do Parque Nacional do Caparaó. Disponível em http://www.terrabrasilis.org.br/ecotecadigital/pdf/ planomanejoparquecaparao.pdf (acesso em 28-III-2018).

Judd, W.S., Campbell, C.S., Kellogg, E.A., Stevens, P.F. \& Donoghue, M.J. 2009. Sistemática Vegetal: Um Enfoque Filogenético. 3 ed. Porto Alegre: Artmed.

Leoni, L. \& Chautems, A. 2004. Flora Fanerógama do Parque Nacional do Caparaó: Gesneriaceae. Pabstia, 15: 1-11.

Lorenzi, H. 1991. Plantas daninhas do Brasil: terrestres, aquáticas, parasitas, tóxicas e medicinais. 2 ed. Editora Plantarum, Nova Odessa.

Luizi-Ponzo, A.P. 1997. Verbenaceae. In: M.C.M. Marques, A.S.F. Vaz \& R. Marquete (eds.). Flórula da APA Cairuçu, Parati, Rio de Janeiro. Instituto de Pesquisas Jardim Botânico do Rio de Janeiro. Série Estudos e Contribuições 14: 558-564.

Mazine, F.F. \& Castro V.C. 2008. Myrtaceae dos campos de altitude do Parque Nacional do Caparaó-Espirito Santo/Minas Gerais, Brasil. Rodriguesia 59: 57-74.

Melo, J.I.M., Alves, I.M, Sousa, R.T.M., Barbosa, L.M.M.A. \& Andrade, W.M. 2010. Verbenaceae sensu lato em um trecho da ESEC Raso da Catarina, Bahia, Brasil. Revista Caatinga 23: 41-47.

Mota, T.M. 2012. A flora de Bromeliaceae no Parque Nacional do Caparaó, MG/ES: Tratamento taxonômico e influência das variáveis climáticas na composição de espécies no sudeste brasileiro. Dissertação de Mestrado. Universidade Federal de Minas Gerais.

Mota, T.M., Forzza, R.C. \& Stehmann, J.R. 2016. Bromeliaceae from Caparaó National Park, Minas Gerais/Espírito Santo states, Brazil, with notes on distribution and conservation. Oecologia Australis 20: 271-284. 
O'Leary, N. \& Keller, H.A. 2018. Primer registro de Citharexylum solanaceum (Verbenaceae) para la flora Argentina. Darwiniana 6: 108-112.

O’Leary, N., Múlgura, M.E. \& Morrone, O. 2007. Revisión taxonómica de las espécies del -género Verbena L. (Verbenaceae): serie Pachystachyae. Annals of the Missouri Botanical Garden 94: 571-622.

O'Leary, N. \& Thode, V. 2016. The genus Glandularia (Verbenaceae) in Brazil. Annals of the Missouri Botanical Garden 101: 699-749.

Olmstead, R.G., Jansen, R.K., Kim, K.J. \& Wagstaff, S.J. 2000. The phylogeny of the Asteridae s.l. based on chloroplast ndh F sequences. Molecular Phylogenetics and Evolution 16: 96-112.

Radford A.E., Dickinson, W.C., Massey, J.R. \& Bell, C.R. 1974. Vascular Plant Systematics. Harper Collins, New York.

Romão, G. O., \& Souza, V. C. 2003. Flora fanerogâmica do Parque Nacional do Caparaó: Ericaceae. Pabstia, 14: 1-12.

Salimena, F.R.G. \& Giulietti, A.M. 1998. Flora da Serra do Cipó, Minas Gerais: Verbenaceae. Boletim de Botânica da Universidade de São Paulo 17: 155-186.

Salimena, F.R.G. 2000. Verbenaceae. In: M.M.R.F. Melo, F. Barros, M.G.L. Wanderley, M. Kirizawa, S.L. Jung Mendaçolli \& S.A.C. Chiea (eds.). Flora fanerogâmica da Ilha do Cardoso, São Paulo. v. 7. Instituto de Botânica, São Paulo, pp. 7-26.

Salimena, F.R.G., Dias, A.M., Múlgura, M.E., Ferreira, S.C. \& Silva, T.R.S. 2015. Verbenaceae. In: T.B. Cavalcante \& A.C. Amaral-Lopes (eds.). Flora do Distrito Federal, Brasil. v. 12, Embrapa, Brasília, pp. 83-132.

Salimena, F.R.G., Ferreira, S.C., Cardoso, P.H. \& Valério, V.I.R. 2016. Verbenaceae. In: J.A. Rizzo (ed.). Flora dos estados de Goiás e Tocantins. Coleção Rizzo. v. 47. Universidade Federal de Goiás, Goiânia, pp. 1-157.
Sanders, R.W. 2001. The genera of Verbenaceae in the southeastern United States. Harvard Papers in Botany 5: 303-358.

Sanders, R,W. 2012. Taxonomy of Lantana sect. Lantana (Verbenaceae): II. Taxonomic revision. Journal of the Botanical Research Institute of Texas 6: 403-441.

Santos, E.M.B. 2004. Parque Nacional do Caparaó: histórias de um lugar. HALAC 3: 117-143.

Santos, J.S., Melo, J.I.M., Abreu, M.C. \& Sales, M.F. 2009. Verbenaceae sensu stricto na região de Xingó: Alagoas e Sergipe, Brasil. Rodriguésia 60: 985-998.

Schauer, J.C. 1847. Verbenaceae. In: A.P. Candolle (ed.). Prodromus systematis naturalis regni vegetabilis. Victor Masson, Paris. v. 11. pp. 522-700.

Silva, T.R.S. 1999. Redelimitação e revisão taxonômica do gênero Lantana L. (Verbenaceae) no Brasil. Tese de Doutorado, Universidade de São Paulo, São Paulo.

Saout, S., Hoffmann, M., Shi, Y., Hughes, A., Bernard, C., Brooks, T. M., Bertzky, B., Butchart, S.H.M., Stuart, S.N., Badman, T. \& Rodrigues, A.S.L. 2013. Protected areas and effective biodiversity conservation. Science 342: 803-805.

Souza, J.P. \& Souza, V.C. 2000. Flora Fanerogâmica do Parque Nacional do Caparaó: Violaceae. Pabstia 11: 1-7.

Thiers, B. 2019. Index Herbariorum: A global directory of public herbaria and associated staff.New York Botanical Garden's Virtual Herbarium. Disponível em http:// sweetgum.nybg.org/ih/ (acesso em 28-III-2019).

Souza, J. P., \& Souza, V. C. 2002. Flora fanerogâmica do Parque Nacional do Caparaó: Plantaginaceae. Pabstia 13: $1-5$.

Trovó, M., Sano, P.T., Costa, F.N., \& Giulietti, A.M. 2006. Flora fanerogâmica do Parque Nacional do Caparaó. Eriocaulaceae. Pabstia 17: 2-8.

Wagstaff, S.J., \& Olmstead, R.G. 1997. Phylogeny of Labiatae and Verbenaceae inferred from rbcL sequences. Systematic Botany 22: 165-179. 